\title{
Expression Pattern of Smad4/GATA3 as a Predictor of Survival in Invasive Ductal Carcinoma of the Breast
}

\author{
Kyueng-Whan Min ${ }^{a}$ Dong-Hoon Kim ${ }^{b}$ Sung-Im Do ${ }^{b}$ Seoung Wan Chae ${ }^{b}$ \\ Kyungeun Kim ${ }^{b}$ Jin Hee Sohn ${ }^{b}$ Hyun Joo Lee ${ }^{b}$ In-Gu Do ${ }^{b}$ Jung-Soo Pyo ${ }^{b}$ \\ Yuil Kim ${ }^{b}$ Dong Hyun Kim ${ }^{b}$ Jung-Ho Yang ${ }^{b}$ Sang-Jo Lee ${ }^{b}$ Young Ha $\mathrm{Oh}^{a}$ \\ Sukjoong Oh ${ }^{c}$ Seon Hyeong Choi ${ }^{d}$ Yong Lai Park ${ }^{\mathrm{e}}$ Chan Heun Park ${ }^{\mathrm{e}}$ \\ Eun-Kyung Kim ${ }^{f}$ Mi Jung Kwon ${ }^{g}$ Jinwon Seo ${ }^{g}$ \\ a Department of Pathology, Hanyang University Guri Hospital, Hanyang University College of Medicine, \\ Guri, Departments of b Pathology, ' Internal Medicine, d Radiology and 'Surgery, Kangbuk Samsung Hospital, \\ Sungkyunkwan University School of Medicine, and ${ }^{\mathrm{f} D e p a r t m e n t ~ o f ~ P a t h o l o g y, ~ E u l j i ~ G e n e r a l ~ H o s p i t a l, ~ E u l j i ~ U n i v e r s i t y ~}$ \\ School of Medicine, Seoul, and ${ }^{9}$ Department of Pathology, Hallym University Sacred Heart Hospital, Hallym \\ University College of Medicine, Anyang, Republic of Korea
}

\section{Keywords}

Smad4 protein $\cdot$ GATA3 protein $\cdot$ Prognosis $\cdot$ Breast cancer

\begin{abstract}
Background: Smad4 and GATA3 proteins are known prognostic markers in various cancers. Smad4 is a mediator linked to both tumour suppression and progression. GATA3 is a regulator of development and morphogenesis of the mammary gland. We assessed and compared the predictive performance of Smad4 and GATA3 for clinical outcomes in patients with breast cancer. Methods: The combined expression pattern based on Smad4+/- and GATA3+/- was evaluated by immunostaining using breast cancer tissue microarray, and the relationships between protein expression and clinicopathological variables were analysed. Results: Smad4 expression was only associated with an ill-defined tumour border, whereas GATA3 was associated with several good prognostic fac-
\end{abstract}

\section{KARGER}

(C) 2017 S. Karger AG, Basel

E-Mail karger@karger.com

www.karger.com/pat tors. On analysis of combined markers, there was a significant difference in the expression of fascin (an important factor for cancer invasiveness) between the Smad4+/GATA3- and Smad4-/GATA3+ groups. Smad4+/GATA3- was correlated with worse clinicopathological parameters, relapse-free survival (RFS), and overall survival (OS), compared to Smad4-/ GATA3+. Conclusion: Combined markers of Smad4/GATA3 showed a superior performance compared to single markers for predicting RFS and OS in patients with breast cancer.

(c) 2017 S. Karger AG, Basel

\section{Introduction}

Breast cancer accounts for 23\% of total cancer cases and is the most common cause of cancer death among females [1]. According to the hormonal status, histological type, and American Joint Committee on Cancer

Dong-Hoon Kim, MD, PhD

Department of Pathology, Kangbuk Samsung Hospital

Sungkyunkwan University School of Medicine, 29 Saemunan-ro, Jongno-Gu

Seoul 03181 (Republic of Korea)

E-Mail idavid.kim@samsung.com 
(AJCC) stage, patients with breast cancer receive appropriate treatment such as chemotherapy, radiotherapy, and surgery. Recently, molecular techniques have facilitated the identification of tumour markers that can increase diagnostic performance, including tumour classification, in addition to predicting prognosis and therapeutic response $[2,3]$. Differential expression of various proteins has contributed to the development of more efficient treatment options [4].

Several studies using different biomarkers have revealed relationships with clinical parameters and prognosis in breast cancer [5, 6]. Invasive ductal carcinoma (IDC) is the most common type of breast cancer and is characterised by profound heterogeneity [7]. However, considering the multifactorial origin and diversity of breast cancers, prognostic models based on a specific marker are still debated. Therefore, the use of combined markers based on molecular mechanisms may provide greater insight into the development and progression of malignancy and clinical outcomes $[8,9]$.

The tumour suppressor Smad4 belongs to the family of downstream mediators of transforming growth factor (TGF) and is an important multifunctional cytokine that regulates cell proliferation, differentiation, extracellular matrix production, and the development of carcinoma [10]. Several studies have demonstrated that Smad4 inactivation is significantly correlated with tumourigenesis, especially in pancreatic [11] and colorectal [12] cancer. Various proteins associated with Smad4 have been reported, but the regulatory mechanisms involving Smad4interacting proteins remain unclear. A recent study demonstrated that GATA3 abrogated TGF- $\beta$-Smad signalling by abolishing the interactions between Smad4 and DNA elements linked to fascin function [9]. GATA3 is a zinc finger transcription factor that regulates tumour growth inhibition as well as the development and morphogenesis of the mammary glands [13]. In contrast, fascin, as a prometastasis actin bundling protein, is a predictor of relatively worse prognosis in breast cancer [14]. On the basis of in vitro experimental results [9], we hypothesised that GATA3 expression would reduce Smad4 expression and thereby also inhibit fascin expression in human breast cancer. Combined assessment of Smad4 and GATA3 expression provides more detailed information for predicting clinical outcomes in breast cancer than expression of either marker alone. The aim of this study was to investigate the expression patterns of Smad4 and GATA3, as well as the Smad4-mediated fascin level, in patients with breast cancer. Furthermore, we evaluated whether combinatorial expression is associated with patient survival.

\section{Materials and Methods}

Patient Selection and Characteristics

Clinicopathological findings were collected from patient medical records for 226 cases diagnosed with IDC at Kangbuk SMC between 2000 and 2005. Treatments for IDC included modified radical mastectomy in 205 patients and breast-conserving surgery with axillary lymph node dissection in 21 patients. The clear boundaries of tumour borders on gross examination were referred to as "well-defined" while the blurry ones were referred to as "illdefined."

The histologic grade was determined according to the modified Bloom-Richardson-Elston grading system [15]. Tumours were staged with reference to the size and/or extent of tumour (T), regional lymph node involvement $(\mathrm{N})$, and metastasis $(\mathrm{M})$ using the 7 th AJCC staging system. After surgery, 224 patients received adjuvant treatment such as chemotherapy, trastuzumab, or tamoxifen. Fifty-five patients developed local recurrence and/or new distant metastases. Forty-seven patients died during the follow-up period.

\section{Tissue Microarray Construction}

A series of tumour tissue microarray (TMA) specimens were assembled using a tissue-array instrument (AccuMac Arrayer; ISU ABXIS Co. Ltd., Seoul, Korea). Tumour TMAs consisted of $10 \times 6$ arrays of $2.0-\mathrm{mm}$ tissue cores from representative paraffin blocks. Taking into account the limitations associated with obtaining representative areas of a tumour, we used duplicate 2.0 - $\mathrm{mm}$-diameter tissue cores from each donor block. The percentage of tumour in the tissue cores was $>70 \%$.

\section{Immunohistochemical Staining and Scoring}

Immunostaining with antibodies against human epidermal growth factor receptor 2 (HER2; 1:200; SP3 Clone; Labvision), oestrogen receptor (ER; 1:200; SP1 Clone; Labvision, Fremont, CA, USA), progesterone receptor (PR; 1:200; PgR636 Clone; Dako, Glostrup, Denmark), Ki-67 (1:500; MIB-1 Clone; Dako), and p53 (1:5,000; DO-7 Clone; Dako) was performed using a Dako Autostainer with a Universal Staining System (DakoCytomation, Carpinteria, CA, USA) and a ChemMate ${ }^{\mathrm{TM}}$ DAKO EnVision ${ }^{\mathrm{TM}}$ Detection Kit. Immunostaining of ER, PR, and HER-2 was assessed based on the American Society of Clinical Oncology/College of American Pathologists guidelines $[16,17]$. Repeat testing was performed if results were discordant with other histopathological findings.

For this study, positive immunostaining with antibodies against GATA3 (1:100; L50-823; Cell Marque, Rocklin, CA, USA) and Smad4 (1:100; EP618Y; Abcam, Cambridge, UK) was defined as only nuclear staining regardless of the cytoplasmic staining. We used human lung carcinoma and urothelium (transitional epithelium), respectively, for positive controls of Smad4 and GATA3, while we adopted tonsil and placental tissue as negative controls.

Positivity for anti-fascin antibody (1:500; clone 55K-2; Dako) was defined as exclusive cytoplasmic staining without nuclear staining. The expression of $\operatorname{Smad} 4$ was graded according to both the intensity and percentage of positively stained tumour cells [18]. The intensity of nuclear staining was recorded separately as follows: 0 (no staining), 1 (weak), 2 (moderate), or 3 (strong). The extent of staining was graded as follows: $0(0-5 \%), 1(6-25 \%), 2$ (26-50\%), 3 (51-75\%), or 4 (>75\%; Fig. 1). The combined immunoreactive score (IRS) was generated by multiplying the score for

Smad4 and GATA3 in Breast Cancer

Pathobiology 2017;84:130-138 

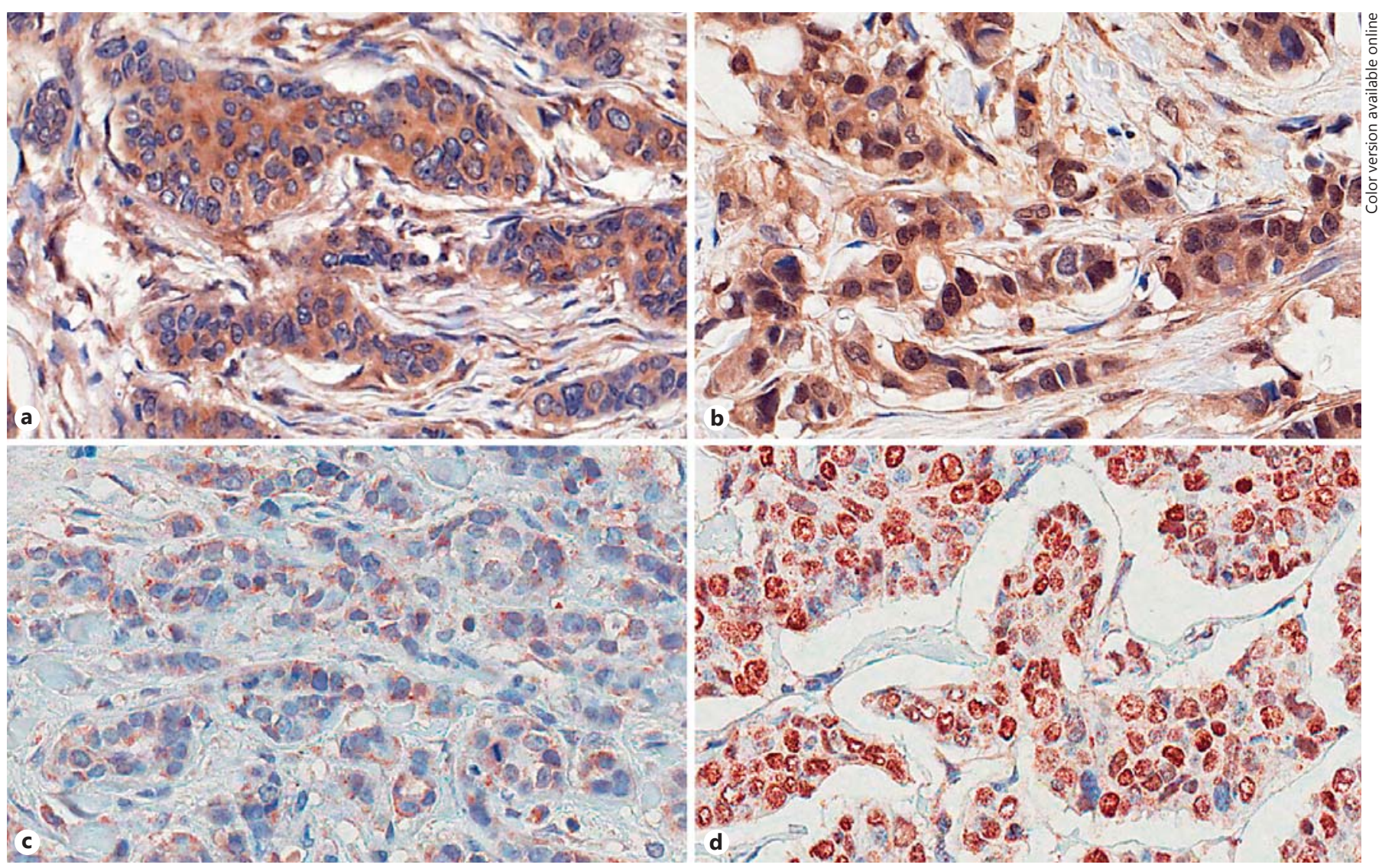

Fig. 1. Micrographs showing negative (a) and positive (b) Smad4 nuclear expression, and negative (c) and positive (d) GATA3 nuclear expression by immunohistochemical staining of breast cancer specimens. Original magnification. $\times 200$.

intensity by the score for extent. When a discrepancy occurred between duplicate cores, the higher score from the 2 tissue cores was used as the final score. Molecular subtypes were classified as follows: luminal A (ER+ and/or PR+, HER2-, Ki-67 <14\%), luminal B HER2- (ER+ and/or PR+, HER2-, Ki-67 $\geq 14 \%)$, luminal B HER2+ (ER+ and/or PR+, HER2+, any Ki-67), HER2+ (ER- and PR-, HER2+), and triple-negative (ER-, PR-, and HER2-) [19, 20]. On the basis of published data, immunoreactivity for GATA3 was divided into "negative" (expression <50\%) and "positive" (expression $\geq 50 \%$ ) [21]. p53 defined nuclear staining of tumour cells as positive. Positive fascin immunostaining was defined as exclusive cytoplasmic staining with no nuclear staining.

We used receiver-operating characteristic (ROC) curves for determination of the optimal cut-off of Smad4. The cut-off value calculated using the ROC curve was used to evaluate the relationship between Smad4 and survival (area under the ROC: 0.594). On the basis of the ROC curve, Smad4 expression was classified as "negative" (IRS $\leq 5$ ) or "positive" (IRS $>5$ ).

Statistical Analysis

Categorical variables were compared using the $\chi^{2}$ test and linear by linear association test. Continuous variables such as $\mathrm{p} 53$ and fascin expression were compared using the Student $t$ test. In sur- vival analyses, plots were generated using the Kaplan-Meier curve and were compared using the log-rank test. Multivariate analysis was performed to identify independent prognostic markers for relapse-free survival (RFS) and overall survival (OS) using a Cox multistep regression model. A value of $p<0.05$ was considered statistically significant. All statistical analyses were performed using the R package (http://www.r-project.org/) and SPSS version 20.0 (SPSS Inc., Chicago, IL, USA).

\section{Results}

\section{Clinicopathological Characteristics Associated with}

Smad4 and GATA3 Expression

Smad4 expression was associated with an ill-defined tumour border. GATA3 expression was correlated with good prognostic parameters such as young age, low histological grade, and the absence of vascular invasion and necrosis (all $p<0.05$ ). ER+ and PR+ and HER2- was not linked to Smad4, but was significantly related to GATA3
Min et al. 


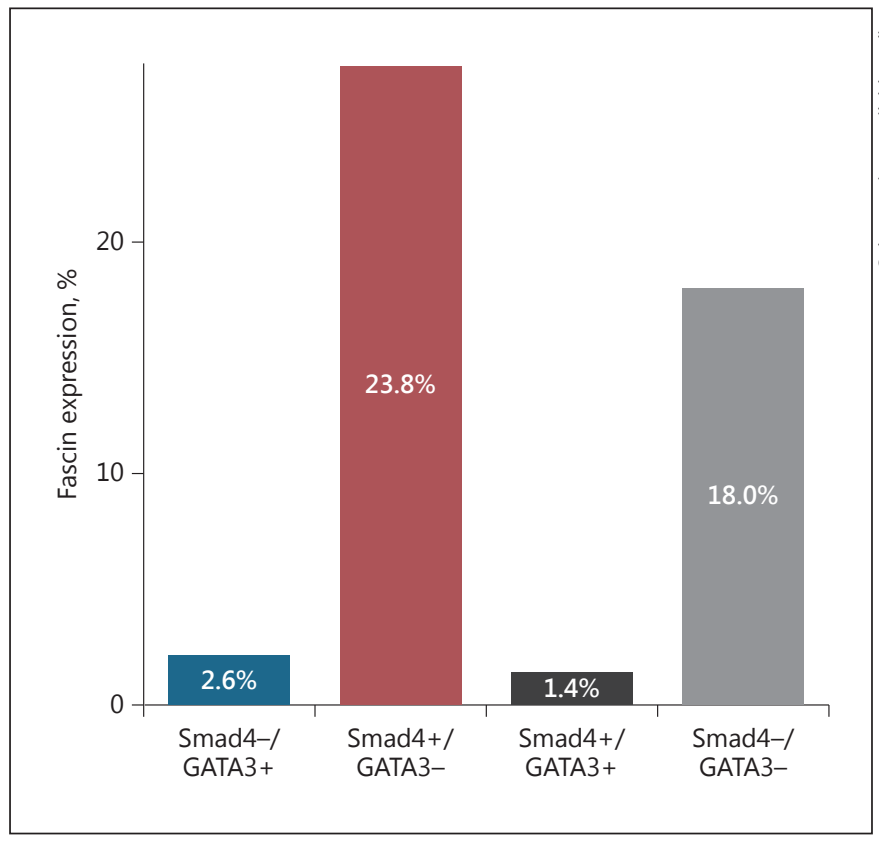

Fig. 2. Fascin is highly expressed in the Smad4+/GATA3- group compared with the Smad4-/GATA3+ group $(p<0.001)$.

(all $p<0.05$; online suppl. Table 1; for all online suppl. material, see www.karger.com/doi/10.1159/000449428). The expression of p53 was higher in the Smad4+ group than in the Smad4- group, but the difference was not statistically significant $(p=0.274)$. p53 expression was higher in the GATA3 - group than in the GATA3+ group $(p=$ $0.003)$.

A comparison of Smad4 and GATA3 expression revealed an inverse relationship, but it was not statistically significant $(p=0.621)$. Comparison of molecular subgroups showed that Smad4 expression was more frequently observed in the luminal B HER2- and HER2+ subgroup than in the HER2+ group. GATA3 expression was rare in the HER 2 and triple-negative subgroups compared with the other subgroups.

\section{Comparison of Clinicopathological Parameters and \\ Expression Pattern of Smad4/GATA3}

Patients were divided into 4 groups according to the expression pattern of Smad4 and GATA3: Smad4-/ GATA3+ $(n=45)$, Smad4+/GATA3 $-(n=55)$, Smad4 + / GATA3 $+(n=71)$, and Smad4-/GATA3- $(n=55)$.

On comparison of the Smad4-/GATA3+ and Smad4+/ GATA3 - groups, Smad4+/GATA3 - was associated with a high histological grade, vascular and perineural invasion, tumour necrosis, ER- and PR-, HER2+, and high
Table 1. Correlation between clinicopathological parameters and Smad4 and GATA3 expression

\begin{tabular}{|c|c|c|c|c|}
\hline Parameter & $n=100$ & $\begin{array}{l}\text { Smad4-l } \\
\text { GATA3+ } \\
(n=45)\end{array}$ & $\begin{array}{l}\text { Smad4+l } \\
\text { GATA3- } \\
(n=55)\end{array}$ & $\begin{array}{l}p \text { value } \\
\left(\chi^{2} \text { test }\right)\end{array}$ \\
\hline \multicolumn{5}{|l|}{ Age } \\
\hline$\leq 50$ years & 60 & $29(48.3)$ & $31(51.7)$ & \multirow[t]{2}{*}{0.412} \\
\hline$>50$ years & 40 & $16(40)$ & $24(60)$ & \\
\hline \multicolumn{5}{|l|}{$\mathrm{T}$ category } \\
\hline 1 & 41 & $16(39)$ & $25(61)$ & \multirow[t]{3}{*}{$0.799^{\mathrm{a}}$} \\
\hline 2 & 53 & $28(52.8)$ & $25(47.2)$ & \\
\hline 3 & 6 & $1(16.7)$ & $5(83.3)$ & \\
\hline \multicolumn{5}{|l|}{$\mathrm{N}$ category } \\
\hline 0 & 48 & $21(43.8)$ & $27(56.2)$ & \multirow[t]{4}{*}{$0.803^{\mathrm{a}}$} \\
\hline 1 & 30 & $16(53.3)$ & $14(46.7)$ & \\
\hline 2 & 11 & $3(27.3)$ & $8(72.7)$ & \\
\hline 3 & 11 & $5(45.5)$ & $6(54.5)$ & \\
\hline \multicolumn{5}{|l|}{ Tumour border } \\
\hline Well defined & 21 & $13(61.9)$ & $8(38.1)$ & \multirow{2}{*}{0.08} \\
\hline Ill defined & 79 & $32(40.5)$ & $47(59.5)$ & \\
\hline \multicolumn{5}{|l|}{ Number of tumours } \\
\hline Single & 91 & $40(44)$ & $51(56)$ & \multirow[t]{2}{*}{$0.728^{\mathrm{b}}$} \\
\hline Multiple & 9 & $5(55.6)$ & $4(44.4)$ & \\
\hline \multicolumn{5}{|l|}{ Histologic grade } \\
\hline 1 & 18 & $10(55.6)$ & $8(44.4)$ & \multirow[t]{3}{*}{$0.006^{\mathrm{a}}$} \\
\hline 2 & 47 & $27(57.4)$ & $20(42.6)$ & \\
\hline 3 & 35 & $8(22.9)$ & $27(77.1)$ & \\
\hline \multicolumn{5}{|l|}{ Lymphatic invasion } \\
\hline Negative & 51 & $26(51)$ & $25(49)$ & \multirow[t]{2}{*}{0.22} \\
\hline Positive & 49 & $19(38.8)$ & $30(61.2)$ & \\
\hline \multicolumn{5}{|l|}{ Vascular invasion } \\
\hline Negative & 93 & $45(48.4)$ & $48(51.6)$ & \multirow[t]{2}{*}{$0.016^{\mathrm{b}}$} \\
\hline Positive & 7 & $0(0)$ & $7(100)$ & \\
\hline \multicolumn{5}{|l|}{ Perineural invasion } \\
\hline Negative & 85 & $42(49.4)$ & $43(50.6)$ & \multirow[t]{2}{*}{0.035} \\
\hline Positive & 15 & $3(20)$ & $12(80)$ & \\
\hline \multicolumn{5}{|l|}{ Tumour necrosis } \\
\hline Absence & 62 & $33(53.2)$ & $29(46.8)$ & \multirow[t]{2}{*}{0.035} \\
\hline Presence & 38 & $12(31.6)$ & $26(68.4)$ & \\
\hline \multicolumn{5}{|c|}{ Central tumour fibrosis } \\
\hline Absence & 84 & $37(44)$ & $47(56)$ & 0.661 \\
\hline Presence & 16 & $8(50)$ & $8(50)$ & \\
\hline EIC & & & & \\
\hline Absence & 85 & $37(43.5)$ & $48(56.5)$ & 0.482 \\
\hline Presence & 15 & $8(53.3)$ & $7(46.7)$ & \\
\hline ER & & & & \\
\hline Negative & 30 & $0(0)$ & $30(100)$ & $<0.001$ \\
\hline Positive & 70 & $45(64.3)$ & $25(35.7)$ & \\
\hline PR & & & & \\
\hline Negative & 44 & $8(18.2)$ & $36(81.8)$ & $<0.001$ \\
\hline Positive & 56 & $37(66.1)$ & $19(33.9)$ & \\
\hline HER2 & & & & \\
\hline Negative & 77 & $39(50.6)$ & $38(49.4)$ & 0.038 \\
\hline Positive & 23 & $6(26.1)$ & $17(73.9)$ & \\
\hline p53 expression, \% & & 11.36 & 35.09 & $<\mathbf{0 . 0 0 1}^{\mathrm{c}}$ \\
\hline Fascin expression, \% & & 2.16 & 27.65 & $<\mathbf{0 . 0 0 1}^{\mathrm{c}}$ \\
\hline
\end{tabular}

Values in parentheses are percentages. EIC, extensive intraductal component; ER, oestrogen receptor; PR, progesterone receptor; HER2, human epidermal growth factor receptor 2. $p$ values $<0.05$ are shown in bold.

${ }^{\mathrm{a}}$ Linear by linear association.

${ }^{\mathrm{b}}$ Fisher exact test.

c Student $t$ test.

Pathobiology 2017;84:130-138 DOI: $10.1159 / 000449428$ 
Table 2. Expression of Smad4 and GATA3 according to molecular subtype

\begin{tabular}{llllll}
\hline Expression & Luminal A & $\begin{array}{l}\text { Luminal B } \\
\text { HER2- }\end{array}$ & $\begin{array}{l}\text { Luminal B } \\
\text { HER2 }+\end{array}$ & HER2 & Triple negative \\
\hline Cases, $n$ & 116 & 8 & 29 & 32 & 41 \\
Smad4-/GATA3+ & $37(31.9)$ & $2(25)$ & $6(20.7)$ & - & - \\
Smad4+/GATA3- & $15(12.9)$ & $3(37.5)$ & $7(24.1)$ & $10(31.2)$ & $20(48.8)$ \\
Smad4+/GATA3+ & $51(44)$ & $2(25)$ & $12(41.4)$ & $5(15.6)$ & $1(2.4)$ \\
Smad4-/GATA3- & $13(11.2)$ & $1(12.5)$ & $4(13.8)$ & $17(53.1)$ & $20(48.8)$ \\
\hline
\end{tabular}

Values in parentheses are percentages. HER2, human epidermal growth factor receptor 2.

Table 3. RFS and OS analyses according to combined markers of Smad4 and GATA3

\begin{tabular}{|c|c|c|c|c|}
\hline & $\begin{array}{l}\text { Univariate } \\
\text { significance }^{\mathrm{a}}\end{array}$ & $\begin{array}{l}\text { Multivariate } \\
\text { significance }^{\mathrm{b}}\end{array}$ & $\begin{array}{l}\text { Relative } \\
\text { risk }\end{array}$ & $95 \% \mathrm{CI}$ \\
\hline \multicolumn{5}{|l|}{ RFS } \\
\hline Smad4-/GATA3+ vs. Smad4+/GATA3- & $<0.001$ & 0.003 & 7.141 & $1.95-26.15$ \\
\hline AJCC stage (I or II vs. III) & 0.028 & 0.227 & 1.744 & $0.708-4.297$ \\
\hline Histological grade ( 1 or 2 vs. 3 ) & 0.051 & 0.758 & 0.842 & $0.283-2.508$ \\
\hline Lymphatic invasion (absence vs. presence) & 0.084 & 0.636 & 1.276 & $0.465-3.497$ \\
\hline Perineural invasion (absence vs. presence) & $<0.001$ & 0.01 & 3.171 & $1.313-7.662$ \\
\hline Oestrogen receptor (absence vs. presence) & 0.05 & 0.679 & 1.22 & $0.476-3.125$ \\
\hline \multicolumn{5}{|l|}{ OS } \\
\hline Smad4-/GATA3+ vs. Smad4+/GATA3- & 0.001 & 0.04 & 9.509 & $1.109-81.557$ \\
\hline AJCC stage (I or II vs. III) & 0.073 & 0.508 & 1.478 & $0.464-4.707$ \\
\hline Histological grade ( 1 or 2 vs. 3 ) & 0.029 & 0.641 & 0.707 & $0.165-3.033$ \\
\hline Lymphatic invasion (absence vs. presence) & 0.118 & 0.723 & 1.277 & $0.331-4.934$ \\
\hline Perineural invasion (absence vs. presence) & $<0.001$ & 0.018 & 4.025 & $1.274-12.716$ \\
\hline Oestrogen receptor (absence vs. presence) & 0.003 & 0.415 & 0.619 & $0.196-1.960$ \\
\hline
\end{tabular}

p53 expression (all $p<0.05$; Table 1). Interestingly, fascin, a poor prognostic marker, was highly expressed in the Smad4+/GATA3- subgroup compared to Smad4-/ GATA3+ $(p<0.001$; Fig. 2$)$. In a comparative analysis between the Smad4+/GATA3- and Smad4+/GATA3+ groups, Smad4+/GATA3- was correlated with old age, high histological grade, and ER- and PR- (all $p<0.05)$. In comparative analysis between the Smad4+/GATA3+ and Smad4-/GATA3- groups, Smad4+/GATA3+ was related to young age, ill-defined tumour border, low histological grade, absence of necrosis, ER+, and PR+ (all $p<0.05)$. In comparative analysis between the Smad4-/ GATA3+ and Smad4+/GATA3+ or between Smad4-/
GATA3+ and Smad4-/GATA3- groups, there was a significant difference in tumour border. There was no significant difference in any parameters tested between the Smad4+/GATA3- and Smad4-/GATA3- groups.

In the comparison of molecular subtypes, Smad4-/ GATA3+ was observed in the luminal A, luminal B HER2 - and luminal B HER2+ subtypes, but was not detected in HER2 and triple-negative subtypes (Table 2).

\section{Comparison between Survival and Expression}

Patterns of Smad4 and GATA3

Smad4 expression was associated with short RFS and OS (both $p<0.05)$. GATA3 expression was linked to long 


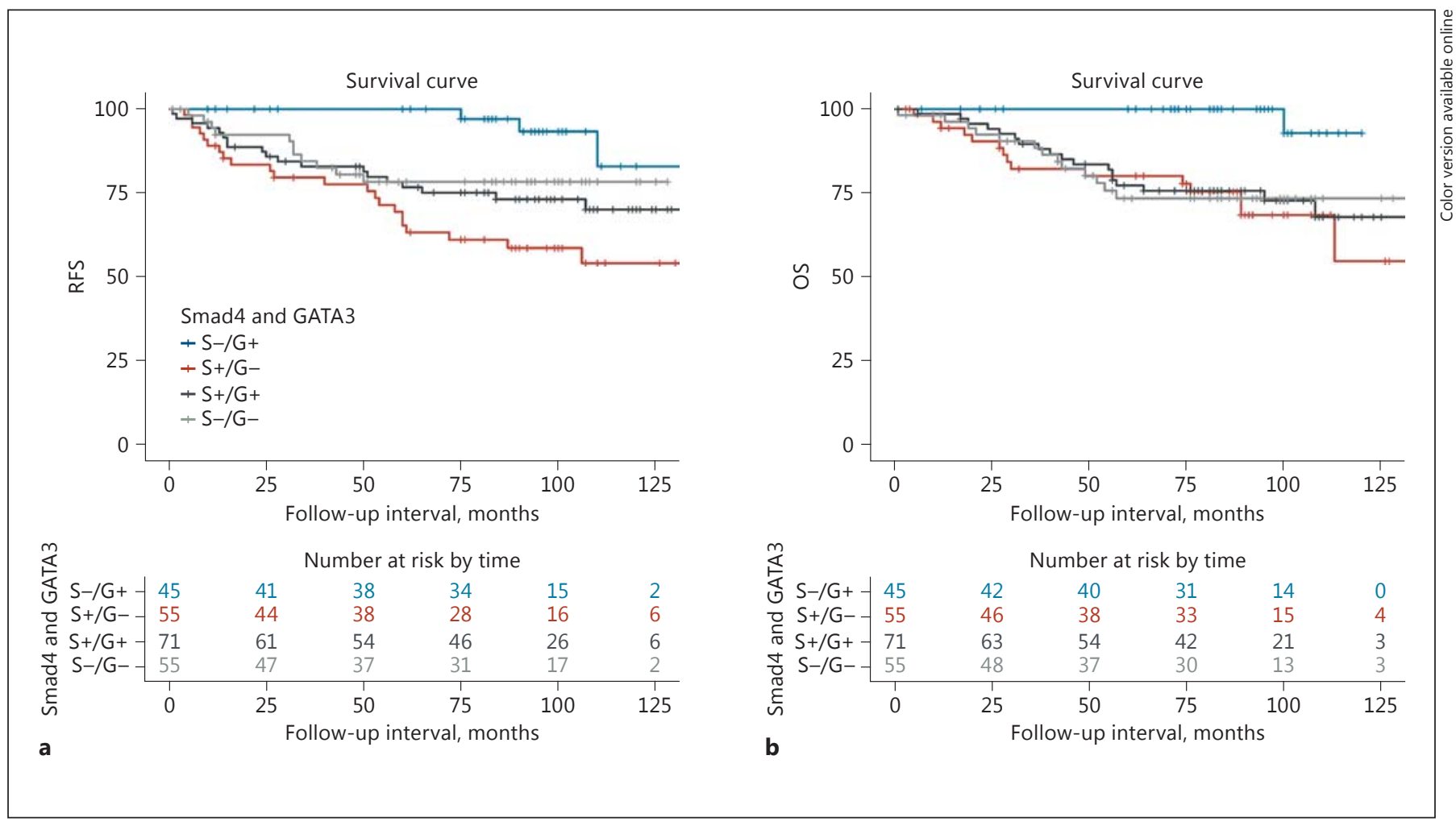

Fig. 3. RFS (a) and OS (b) curves derived via the Kaplan-Meier method showing correlations with expression patterns of Smad4 (S) and GATA3 (G) (Smad4-/GATA3+ vs. Smad4+/GATA3-; all $p<0.05$ ).

RFS ( $p=0.031)$, but not to OS. In multivariate analyses (adjusted for AJCC stage, histological grade, lymphatic and perineural invasion, and ER), there was no relationship between OS and Smad4, but RFS remained associated with Smad4. GATA3 expression did not correlate with RFS (online suppl. Table 2).

In the comparison of the Smad4+/GATA3- and Smad4-/GATA3+ groups, Smad4+/GATA3 - was significantly correlated with poor RFS and OS (both $p<0.05$ ). In multivariate analyses, we still observed a significant correlation between Smad4+/GATA3 - and poor RFS and OS (both $p<0.05$; Table 3). In addition, there were significant differences in RFS and OS between the Smad4-/ GATA3+ and Smad4+/GATA3+ groups and between the Smad4-/GATA3+ and Smad4-/GATA3- groups in the univariate analysis (all $p<0.05$ ); however, these differences were not observed in the multivariate analysis (Fig. 3; online suppl. Table 3). In the luminal A subtype group, there was a difference in RFS between Smad4-/ GATA3+ and Smad4+/GATA3- $(p=0.02)$, but little difference in OS (online suppl. Table 4).

Smad4 and GATA3 in Breast Cancer

\section{Discussion}

The aim of this study was to determine whether any relationship between the expression of Smad4 and GATA3 correlated with clinical outcomes in breast cancer. The Smad4 protein is involved in signal transduction from the cell surface to the nucleus. In the nucleus, a protein complex including Smad4 interacts with the nucleotides of DNA for transcriptional regulation and cell growth or proliferation [22]. GATA3 is necessary for mammary gland morphogenesis and for the maintenance of luminal cell differentiation [23].

Recently, a study by Sun et al. [9] demonstrated that GATA3 abrogated Smad4-mediated overexpression of fascin. Suppression of the canonical TGF- $\beta$-Smad signalling axis by GATA3 could potentially reduce active cellular migration and invasiveness in breast cancer cells. Fascin, the end product of the signalling axis, is related to cellular migration and invasion [24]. On the other hand, loss or low expression of GATA3 could promote fascininduced invasiveness associated with poor clinical outcomes [25]. Therefore, it appears that Smad4, functioning

Pathobiology 2017;84:130-138 DOI: $10.1159 / 000449428$ 
as a signal transduction mediator, plays an important role in the interaction between GATA3 and fascin. In neoplastic development, Smad4 is a tumour suppressor gene that is mutated or deleted in $50 \%$ of pancreatic cancers [26] and loss of Smad4 expression has been shown to be important for the progression of gastric [27], cervical [28], and colorectal [29] cancers. In addition, homozygous deletions of Smad4 have been detected in approximately $8 \%$ of breast cancers [30]. However, Smad4 is involved in many cell functions, such as gastrulation, differentiation, fibrosis, and extracellular matrix stimulation, according to different interacting genes [31-34]. Although Smad4 mediates the regulation of various cellular functions for cancer progression [9, 35-37], most studies have only focused on the role of Smad4 as a tumour suppressor.

Smad4 plays an important role as both a tumour suppressor and in the progression of breast cancer cells [37]. Previous studies reported that $\mathrm{Smad} 4$ expression appears to be decreased in breast cancer relative to normal tissues and correlates with a good prognosis [38, 39]. However, one study suggested that patients with Smad4- tumours show a trend toward longer survival [40]. Another study demonstrated that loss of Smad signalling is correlated with a decrease in axillary lymph node metastasis [36]. Thus, it was questionable whether the role of Smad4 as only a tumour suppressor could explain the opposing results of previous studies, especially in breast cancer. A few studies have demonstrated that high Smad4 expression correlates to a high histological grade and advanced tumour stage in different types of cancer $[41,42]$. Which target molecule Smad4 is involved with can decide its function as an oncogenic or tumour suppressor. In groups with a negative correlation between Smad4 and GATA3, Smad4 has a greater influence in its tumour progression role along the GATA3-Smad4-fascin signalling pathway than its tumour suppression role. Additionally, the discrepancies might be also explained by several other factors, including study design (e.g., criteria of staining), type of malignancy, and ethnic factors. In the above studies showing a good prognosis, a positive expression of Smad4 was defined as without considering only nuclear expression as the functional form of Smad4.

A prognostic model using a dual marker may be better than one using a single marker for patients with breast cancer. In the present study, the Smad4+/GATA3- status indicated a poor prognosis, whereas the Smad4-/ GATA3+ status was associated with a good prognosis. In human breast cancer, these findings suggest that a high Smad4 level resulting from low GATA3 expression can favour cancer progression according to fascin expression, whereas a low Smad4 level due to high GATA3 expression suppresses tumour cell proliferation and invasion according to fascin expression. In our study, fascin was highly expressed in the Smad4+/GATA3- group, compared with the Smad4-/GATA3+ group. In contrast to our expectations, our data did not show an inverse correlation between Smad4 and GATA3; some cases with Smad4+/GATA3+ or Smad4-/GATA3- expression were observed in this study. In the negative correlation between Smad4 and GATA3 through the GATA3-Smad4fascin signalling pathway (Smad4-/GATA3+vs. Smad4+/ GATA3-), fascin expression was vastly different, which also influenced its survival rate. However, there can exist mechanisms that escape such an inverse correlation (Smad4+/GATA3+ or Smad4-/GATA3-), where the difference in survival rate is small, with a limited impact on fascin. Although it is difficult to understand the full mechanism, double positive (Smad4+/GATA3+) or double negative (Smad4-/GATA3-) can be influenced by signalling pathways that other unknown molecules are involved with. In other words, the functional correlation between Smad4 and GATA3 may not apply in some portion of the TGF- $\beta$ pathway and might depend on a range of environmental factors and/or different proteins linked to currently unknown mechanisms.

Our results revealed an alternative function of Smad4 through the GATA3-Smad4-fascin signalling pathway in human breast cancer. Compared to its role as a tumour suppressor, the outcome of Smad4 activity through this signalling pathway may be affected by the function of its target proteins according to the type of cancer, especially in breast cancer. Moreover, the combined expression pattern of Smad4 and GATA3 was significantly associated with various clinicopathological parameters and patient survival. Therefore, understanding the relationship between Smad4 and GATA3 may be helpful for predicting disease prognosis in patients with breast cancer.

\section{Acknowledgements}

We are grateful to Ina Jeong for editing this manuscript.

This work was supported by Medical Research Funds from Kangbuk Samsung Hospital (No. HIY0150051).

\section{Statement of Ethics}

This study (involving human participants) was approved by the Ethics Committee of the Kangbuk Samsung, Seoul, Republic of Korea (KBSMC 2015-07-035), and was performed according to the ethical standards of the Declaration of Helsinki, as revised in 2008.
136

Pathobiology 2017;84:130-138

DOI: $10.1159 / 000449428$
Min et al. 


\section{Disclosure Statement}

\section{References}

1 Jemal A, Bray F, Center MM, Ferlay J, Ward E, Forman D: Global cancer statistics. CA Cancer J Clin 2011;61:69-90.

2 Peppercorn J, Perou CM, Carey LA: Molecular subtypes in breast cancer evaluation and management: divide and conquer. Cancer Invest $2008 ; 26: 1-10$

3 Naderi A, Teschendorff AE, Barbosa-Morais NL, Pinder SE, Green AR, Powe DG, Robertson JF, Aparicio S, Ellis IO, Brenton JD, Caldas C: A gene-expression signature to predict survival in breast cancer across independent data sets. Oncogene 2007;26:1507-1516.

4 Jemal A, Center MM, DeSantis C, Ward EM: Global patterns of cancer incidence and mortality rates and trends. Cancer Epidemiol Biomarkers Prev 2010;19:1893-1907.

5 Harris L, Fritsche H, Mennel R, Norton L, Ravdin P, Taube S, Somerfield MR, Hayes DF, Bast RC Jr: American Society of Clinical Oncology 2007 update of recommendations for the use of tumor markers in breast cancer. J Clin Oncol 2007;25:5287-5312.

6 Ahn SG, Jeong J, Hong S, Jung WH: Current issues and clinical evidence in tumor-infiltrating lymphocytes in breast cancer. J Pathol Transl Med 2015;49:355-363.

7 Bombonati A, Sgroi DC: The molecular pathology of breast cancer progression. J Pathol 2011;223:307-317.

8 Ali HR, Dawson SJ, Blows FM, Provenzano E, Leung S, Nielsen T, Pharoah PD, Caldas C: A Ki67/BCL2 index based on immunohistochemistry is highly prognostic in ER-positive breast cancer. J Pathol 2012;226:97-107.

9 Sun J, He H, Pillai S, Xiong Y, Challa S, Xu L, Chellappan S, Yang S: GATA3 transcription factor abrogates Smad4 transcription factormediated fascin overexpression, invadopodium formation, and breast cancer cell invasion. J Biol Chem 2013;288:36971-36982.

10 Massague J: TGF $\beta$ signalling in context. Nat Rev Mol Cell Biol 2012;13:616-630.

11 Feldmann G, Beaty R, Hruban RH, Maitra A: Molecular genetics of pancreatic intraepithelial neoplasia. J Hepatobiliary Pancreat Surg 2007;14:224-232.

12 Boulay JL, Mild G, Lowy A, Reuter J, Lagrange $M$, Terracciano L, Laffer U, Herrmann $\mathrm{R}$, Rochlitz C: Smad4 is a predictive marker for 5-fluorouracil-based chemotherapy in patients with colorectal cancer. Br J Cancer 2002;87:630-634.

13 Dydensborg AB, Rose AA, Wilson BJ, Grote D, Paquet M, Giguere V, Siegel PM, Bouchard M: GATA3 inhibits breast cancer growth and pulmonary breast cancer metastasis. Oncogene 2009;28:2634-2642.
The authors have no conflicts of interest to declare.
14 Yoder BJ, Tso E, Skacel M, Pettay J, Tarr S, Budd T, Tubbs RR, Adams JC, Hicks DG: The expression of fascin, an actin-bundling motility protein, correlates with hormone receptor-negative breast cancer and a more aggressive clinical course. Clin Cancer Res 2005;11: 186-192.

15 Robbins P, Pinder S, de Klerk N, Dawkins H, Harvey J, Sterrett G, Ellis I, Elston C: Histological grading of breast carcinomas: a study of interobserver agreement. Hum Pathol 1995;26:873-879.

16 Hammond ME, Hayes DF, Dowsett M, Allred DC, Hagerty KL, Badve S, Fitzgibbons PL, Francis G, Goldstein NS, Hayes M, Hicks DG, Lester S, Love R, Mangu PB, McShane L, Miller K, Osborne CK, Paik S, Perlmutter J, Rhodes A, Sasano H, Schwartz JN, Sweep FC, Taube S, Torlakovic EE, Valenstein P, Viale $\mathrm{G}$, Visscher D, Wheeler T, Williams RB, Wittliff JL, Wolff AC: American Society of Clinical Oncology/College of American Pathologists guideline recommendations for immunohistochemical testing of estrogen and progesterone receptors in breast cancer (unabridged version). Arch Pathol Lab Med 2010;134:e48-e72.

17 Rakha EA, Starczynski J, Lee AH, Ellis IO: The updated ASCO/CAP guideline recommendations for HER2 testing in the management of invasive breast cancer: a critical review of their implications for routine practice. Histopathology 2014;64:609-615.

18 Remmele W, Stegner HE: Recommendation for uniform definition of an immunoreactive score (IRS) for immunohistochemical estrogen receptor detection (ER-ICA) in breast cancer tissue (in German). Pathologe 1987;8: 138-140.

19 Masuda S: Breast cancer pathology: the impact of molecular taxonomy on morphological taxonomy. Pathol Int 2012;62:295-302.

20 Cheang MC, Chia SK, Voduc D, Gao D, Leung S, Snider J, Watson M, Davies S, Bernard PS, Parker JS, Perou CM, Ellis MJ, Nielsen TO: Ki67 index, HER2 status, and prognosis of patients with luminal B breast cancer. J Natl Cancer Inst 2009;101:736-750.

21 Miettinen M, McCue PA, Sarlomo-Rikala M, Rys J, Czapiewski P, Wazny K, Langfort R, Waloszczyk P, Biernat W, Lasota J, Wang Z: GATA3: a multispecific but potentially useful marker in surgical pathology: a systematic analysis of 2,500 epithelial and nonepithelial tumors. Am J Surg Pathol 2014;38:13-22.

22 Heldin CH, Miyazono K, ten Dijke P: TGF- $\beta$ signalling from cell membrane to nucleus through Smad proteins. Nature 1997;390: 465-471.
23 Kouros-Mehr H, Slorach EM, Sternlicht MD, Werb Z: GATA-3 maintains the differentiation of the luminal cell fate in the mammary gland. Cell 2006;127:1041-1055.

24 Vignjevic D, Schoumacher M, Gavert N, Janssen KP, Jih G, Lae M, Louvard D, BenZe'ev A, Robine S: Fascin, a novel target of $\beta$-catenin-TCF signaling, is expressed at the invasive front of human colon cancer. Cancer Res 2007;67:6844-6853.

25 Min KW, Kim DH, Do SI, Chae SW, Kim K, Sohn JH, Pyo JS, Lee HJ, Kim DH, Oh S, Choi SH, Park YL, Park CH, Kim EK, Kwon MJ, Seo J, Moon KM: Negative association between GATA3 and fascin could predict relapse-free and overall survival in patients with breast cancer. Virchows Arch 2016;468:409-416.

26 Hahn SA, Schutte M, Hoque AT, Moskaluk CA, da Costa LT, Rozenblum E, Weinstein CL, Fischer A, Yeo CJ, Hruban RH, Kern SE: DPC4, a candidate tumor suppressor gene at human chromosome 18q21.1. Science 1996; 271:350-353.

27 Wang LH, Kim SH, Lee JH, Choi YL, Kim YC, Park TS, Hong YC, Wu CF, Shin YK: Inactivation of SMAD4 tumor suppressor gene during gastric carcinoma progression. Clin Cancer Res 2007;13:102-110.

28 Baldus SE, Schwarz E, Lohrey C, Zapatka M, Landsberg S, Hahn SA, Schmidt D, Dienes HP, Schmiegel WH, Schwarte-Waldhoff I: SMAD4 deficiency in cervical carcinoma cells. Oncogene 2005;24:810-819.

29 Salovaara R, Roth S, Loukola A, Launonen V, Sistonen P, Avizienyte E, Kristo P, Jarvinen H, Souchelnytskyi S, Sarlomo-Rikala M, Aaltonen LA: Frequent loss of SMAD4/DPC4 protein in colorectal cancers. Gut 2002;51:56-59.

30 Zhong D, Morikawa A, Guo L, Colpaert C, Xiong L, Nassar A, Chen C, Lamb N, Dong JT, Zhou W: Homozygous deletion of Smad4 in breast cancer cell lines and invasive ductal carcinomas. Cancer Biol Ther 2006;5:601607.

31 Sirard C, de la Pompa JL, Elia A, Itie A, Mirtsos C, Cheung A, Hahn S, Wakeham A, Schwartz L, Kern SE, Rossant J, Mak TW: The tumor suppressor gene Smad4/Dpc4 is required for gastrulation and later for anterior development of the mouse embryo. Genes Dev 1998;12:107-119.

32 Tasca A, Stemig M, Broege A, Huang B, Davydova J, Zwijsen A, Umans L, Jensen ED, Gopalakrishnan R, Mansky KC: Smad1/5 and Smad4 expression are important for osteoclast differentiation. J Cell Biochem 2015;116: 1350-1360. 
33 Goto Y, Manabe N, Uchio-Yamada K, Yamaguchi-Yamada $\mathrm{M}$, Inoue $\mathrm{N}$, Yamamoto $\mathrm{Y}$, Ogura A, Nagano N, Miyamoto H: Augmented cytoplasmic Smad4 induces acceleration of TGF- $\beta 1$ signaling in renal tubulointerstitial cells of hereditary nephrotic ICGN mice with chronic renal fibrosis; possible role for myofibroblastic differentiation. Cell Tissue Res 2004;315:209-221.

34 Tsuchida K, Zhu Y, Siva S, Dunn SR, Sharma K: Role of Smad4 on TGF- $\beta$-induced extracellular matrix stimulation in mesangial cells. Kidney Int 2003;63:2000-2009.

35 Xue J, Lin X, Chiu WT, Chen YH, Yu G, Liu M, Feng XH, Sawaya R, Medema RH, Hung MC, Huang S: Sustained activation of SMAD3/SMAD4 by FOXM1 promotes TGF$\beta$-dependent cancer metastasis. J Clin Invest 2014;124:564-579.
36 Xie W, Mertens JC, Reiss DJ, Rimm DL, Camp RL, Haffty BG, Reiss M: Alterations of Smad signaling in human breast carcinoma are associated with poor outcome: a tissue microarray study. Cancer Res 2002;62:497-505.

37 Deckers M, van Dinther M, Buijs J, Que I, Lowik C, van der Pluijm G, ten Dijke P: The tumor suppressor Smad4 is required for transforming growth factor $\beta$-induced epithelial to mesenchymal transition and bone metastasis of breast cancer cells. Cancer Res 2006;66:2202-2209.

38 Liu NN, Xi Y, Callaghan MU, Fribley A, Moore-Smith L, Zimmerman JW, Pasche B, Zeng Q, Li YL: Smad4 is a potential prognostic marker in human breast carcinomas. $\mathrm{Tu}-$ mour Biol 2014;35:641-650.
39 Liu N, Yu C, Shi Y, Jiang J, Liu Y: Smad4 expression in breast ductal carcinoma correlates with prognosis. Oncol Lett 2015;10:17091715.

40 Stuelten $\mathrm{CH}$, Buck MB, Dippon J, Roberts AB, Fritz P, Knabbe C: Smad4-expression is decreased in breast cancer tissues: a retrospective study. BMC Cancer 2006;6:25.

41 Sheehan GM, Kallakury BV, Sheehan CE, Fisher HA, Kaufman RP Jr, Ross JS: Smad4 protein expression correlates with grade, stage, and DNA ploidy in prostatic adenocarcinomas. Hum Pathol 2005;36:1204-1209.

42 Hiwatashi K, Ueno S, Sakoda M, Kubo F, Tateno T, Kurahara H, Mataki Y, Maemura K, Ishigami S, Shinchi H, Natsugoe S: Strong Smad4 expression correlates with poor prognosis after surgery in patients with hepatocellular carcinoma. Ann Surg Oncol 2009;16: 3176-3182. 